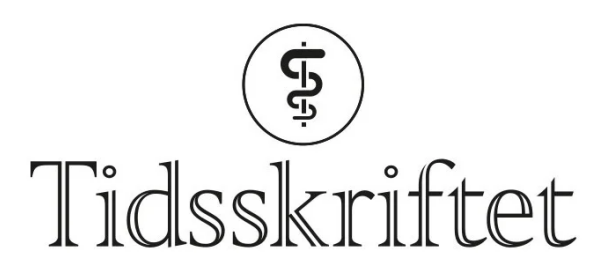

DEN NORSKE LEGEFORENING

\title{
Hva bør gjøres ved mistanke om flåttbåren sykdom?
}

KRONIKK

\section{HARALD REISO}

harald.reiso@sshf.no

Harald Reiso er rådgiver ved Nasjonal kompetansetjeneste for flåttbårne sykdommer ved Sørlandet sykehus, dr.med. og spesialist $i$ allmenn- og samfunnsmedisin.

Forfatter har fylt ut ICMJE-skjemaet og oppgir ingen interessekonflikter.

\section{YVONNE KERLEFSEN}

Yvonne Kerlefsen er rådgiver ved Nasjonal kompetansetjeneste for flåttbårne sykdommer ved Sørlandet sykehus, master i biologi og webredaktør.

Forfatter har fylt ut ICMJE-skjemaet og oppgir ingen interessekonflikter.

\section{AUDUN AASE}

Audun Aase er seniorforsker ved avdeling for metodeutvikling og helseanalyse, Folkehelseinstituttet. Forfatter har fylt ut ICMJE-skjemaet og oppgir ingen interessekonflikter.

\section{INGEBORG S. AABERGE}

Ingeborg S. Aaberge er dr.med. og fagdirektør i Område for smittevern, miljø og helse, Folkehelseinstituttet.

Forfatter har fylt ut ICMJE-skjemaet og oppgir ingen interessekonflikter.

\section{KNUT EIRIK ELIASSEN}

Knut Eirik Eliassen er ph.d., førsteamanuensis ved fagområde for allmennmedisin ved Institutt for global helse og samfunnsmedisin, Universitetet i Bergen, fastlege og spesialist i allmennmedisin. Forfatter har fylt ut ICMJE-skjemaet og oppgir ingen interessekonflikter.

\section{RANDI EIKELAND}

Randi Eikeland er leder av Nasjonal kompetansetjeneste for flåttbårne sykdommer ved Sørlandet sykehus, ph.d. og nevrolog. Hun er førsteamanuensis ved Universitetet i Agder, Fakultet for helse og idrettsfag.

Forfatter har fylt ut ICMJE-skjemaet og oppgir ingen interessekonflikter. 
Fagspesialister og brukere har utarbeidet nordisk konsensus for bedre utredning, behandling og oppfølging av personer med langvarige plager ved mistenkte flåttbårne sykdommer. Det innebærer blant annet forslag om opprettelse av en multidisiplinær spesialpoliklinikk.

Flåttbårne sykdommer er vanlige i Norden. Årlig får 7 ooo personer i Norge en lokal borreliainfeksjon i huden etter flåttbitt, mens om lag 400 får mer utbredte borreliainfeksjoner, som nevroborreliose (1-3). Det er gode og like anbefalinger for diagnostikk, behandling og oppfølging av akutt flåttbåren sykdom i de nordiske landene (4-9.). Dårligere stilt er det for de som har langvarige helseplager som tilskrives sykdom etter flåttbitt (5). En nylig utgitt rapport skal bidra til bedre og mer enhetlig oppfølging av disse (므).

Mange som har langvarige plager ved mistenkte flåttbårne sykdommer opplever at helseproblemene deres ikke håndteres tilfredsstillende $(5, \underline{10})$. En større norsk studie som pågår vedrørende borreliose kartlegger langvarige plager som tilskrives flåttbitt (11). Ved datainnsamling via tekstmeldingsmetode til et utvalg på 270 ooo tilfeldig uttrukne personer i Norge over 18 år, er det 381 som har meldt sin interesse for å bli med i studien, siden de har slike plager (므). De dette gjelder ønsker å bli hørt og trodd på, motta og forstå utredning og behandling samt få en oppfølging som trygger dem. Noen trenger rehabilitering.

På internett er det mange - og sprikende - forklaringsmodeller og behandlingstilbud for flåttbårne sykdommer (13-15). Det er vanskelig å vite hva som er riktig og galt, både for pasienter og helsearbeidere. Noen ganger stilles diagnosen flåttbåren sykdom for seint. Ofte gis diagnosen borreliose på sviktende grunnlag ( $\underline{16-20})$.

"Alternative helsetilbydere er ikke underlagt krav til kvalitetssikring, og har derfor lite fokus på kvalitetskontroll og forskning»

Bruk av alternative helsetilbud er vanlig (211). Erfaringer fra klinikker i Danmark og Nederland, samt Norsk Lyme Borreliose-Forening og Nasjonal kompetansetjeneste for flåttbårne sykdommer (NKFS), tilsier at dette gjelder flere hundre personer årlig i Norden. Dette er problematisk. Alternative helsetilbydere er ikke underlagt krav til kvalitetssikring, og har derfor lite fokus på kvalitetskontroll og forskning. Det brukes tester som ikke er validerte, og gis behandlinger som ikke er evidensbaserte (13-20 $)$. Brukere etterlates uten rettigheter ved feilbehandlinger. Problematikken er ikke særegen for Norden og har vært aktuell i mange år.

Helsedirektoratet fikk i 2013 oppgaven med å følge opp slike problemstillinger knyttet til flåttbårne infeksjoner. Direktoratet arrangerte først en brukerkonferanse. I samråd med brukerne, Folkehelseinstituttet og da nyetablerte Nasjonal kompetansetjeneste for flåttbårne sykdommer, ble det vedtatt å etablere en nordisk ekspertgruppe for å utarbeide konsensus om diagnostikk og behandling av flåttbårne sykdommer. Gruppen ble bredt sammensatt av klinikere i primær- og spesialisthelsetjenesten, brukere, forskere, representanter for Folkehelseinstituttet og helseadministratorer. Ved de første møtene ble det raskt klart at det var god konsensus i Norden om diagnostikk og behandling av akutt borreliose og skogflåttencefalitt (TBE). Mandatet ble derfor spisset til å lage felles nordiske anbefalinger for diagnostikk, behandling og oppfølging av personer med sjeldnere flåttbårne infeksjoner og langvarige plager ved mistenkte flåttbårne sykdommer. 
Dette nordiske konsensusarbeidet anbefaler at utredning og oppfølging av pasienter med langvarige plager ved mistenkt flåttbåren sykdom må være multidisiplinært. Prøver for diagnostikk av andre mulige flåttoverførte infeksjoner enn borreliose og skogflåttencefalitt

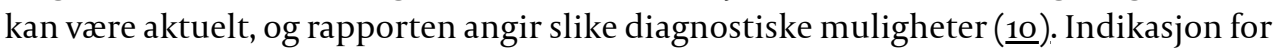
prøver og tolkning av prøvesvar må alltid sees i sammenheng med mulig flåttbitt, aktuell sykehistorie og symptomer. Symptomer og plager etter gjennomgått flåttbåren sykdom kan til forveksling ligne på plager ved mange andre tilstander. Rapporten gir forslag til utredningsforløp for å finne årsaker til pasientenes plager og en sjekkliste til hjelp for henvisende leger. Den vektlegger anbefalinger om oppfølgende kontroller og rehabiliterende tiltak.

\section{Kan plagene skyldes flåttbårne sykdommer?}

Folkehelseinstituttet utførte systematiske litteratursøk på diagnostikk av flåttbårne sykdommer for perioden 2008-2017. Både de vanligste flåttbårne infeksjonene borreliose og skogflåttencefalitt, samt mer sjeldne flåttbårne infeksjoner som anaplasmose, rickettsiose, neoehrlichiose, babesiose, tilbakefallsfeber (ved Borrelia miyamotoi), harepest

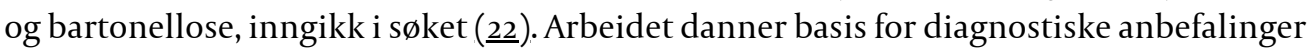
presentert i konsensusrapporten. Systematisk litteraturgjennomgang ble også gjort for samtidig forekomst av flere flåttbårne infeksjoner (koinfeksjoner). Antall diagnostiske studier på koinfeksjoner, samt mer sjeldne flåttbårne sykdommer, er begrenset.

\section{Brukes best tilgjengelig diagnostikk?}

Prøvesvar vurderes ut fra flåtteksponering, sykehistorie og aktuelle symptomer. Noen ganger kan det være vanskelig å vite om man kan stole på testene som er brukt og på prøvesvarene. Hva betyr prøvesvaret, og gir det uttrykk for aktiv sykdom eller ikke? Det kreves at den som tolker prøvesvarene har erfaring med vurderinger av metodene som er brukt, deres sensitivitet og spesifisitet, og diagnostisk betydning av svarene i klinisk praksis. Den som rekvirerer prøvene må også være god til å gi adekvate kliniske opplysninger til laboratoriet. Mange langvarige symptomer knyttet til flåttbårne

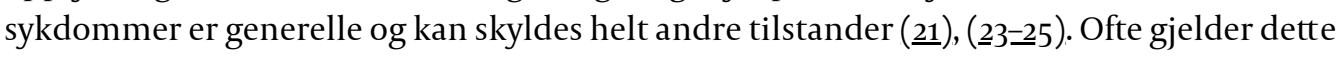
revmatologiske, autoimmune, nevrologiske eller endokrine sykdommer (21). Dette, i kombinasjon med at mange flåttbårne sykdommer er sjeldne og ofte mangelfullt beskrevet i litteraturen, gjør at differensialdiagnostisk tenkning blir avgjørende. Diagnostiske rutiner ved fire spesialistklinikker som jobber med utredning av flåttbårne sykdommer i Norden og Nederland (Odense, Uppsala, Åland og Amsterdam) er vurdert. Resultatene av disse vurderingene kan hjelpe leger å rekvirere riktige tester og unngå bruk av tester som ikke er egnet for diagnostikk av flåttbårne sykdommer.

Noen prinsipper vedrørende diagnostikk og oppfølging overses ofte. For eksempel at diagnosen sikker nevroborreliose ikke kan stilles uten spinalpunksjon, at borreliainfeksjon i huden alltid skal behandles med antibiotika, eller at hudinfeksjonen acrodermatitis chronica atrophicans - med vedvarende rødlilla eller blålig misfarging av hud - kan misoppfattes som venøs stasetilstand når den har stått over år. Acrodermatitis chronica atrophicans skader underhudsvev og gir fortynnet og rynkete hud («sigarettpapirhud»),

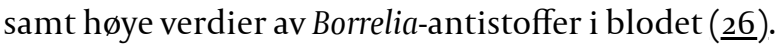

\section{Anbefalt utredningsforløp}


Gode henvisninger er grunnlaget for gode utredninger. Derfor har ekspertgruppen - til hjelp for legen og pasienten - laget en sjekkliste for henvisning av pasienter med langvarige plager ved mistenkte flåttbårne sykdommer samt et flytskjema for anbefalt utredningsforløp (Figur 1) (므), (ㅁ․). Utredningsforløpet har som mål å bekrefte eller avkrefte flåttbåren sykdom som årsak til pasientens plager. Et annet mål er å avdekke andre mulige forklaringer, gi anbefalt behandling og eventuelt rehabilitering. Personer som henvises oppfordres til å skrive en sammenfatning av sin sykehistorie, og hva vedkommende selv oppfatter som årsak til plagene. Denne legges ved henvisningen.

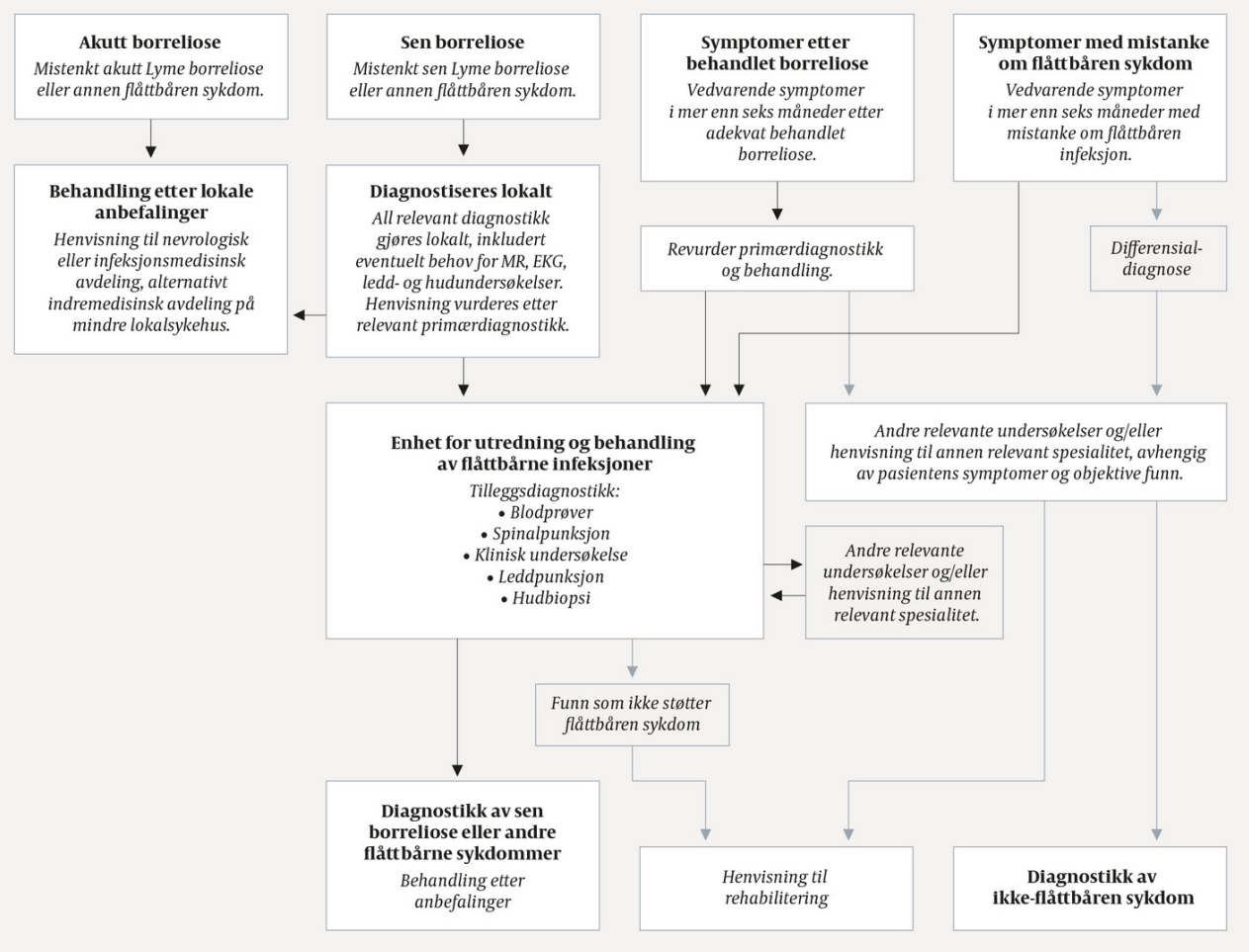

Figur 1 Flytskjema. Anbefalt utredningsforløp for pasienter med vedvarende plager etter mistenkte flåttbårne sykdommer. Etter en skisse av infeksjonsmedisiner Pascal BrüggerSynnes ved Ålesund sykehus, delvis basert på et sveitsisk konsensusdokument vedrørende borreliose (27).

Vi mener det er viktig at pasienter møtes av spesialister som er dedikerte til oppgaven, og at det arbeides multidisiplinært. Best organisering av slikt arbeid oppnås ved å etablere et spesialisert utrednings- og behandlingstilbud for disse pasientene, enten i hver helseregion, eller i et samlet nasjonalt senter.

\section{Oppfølging og rehabilitering}

Etter vår oppfatning tenkes det for lite på rehabiliterende tiltak for personer med langvarige symptomer og plager knyttet til mulig flåttbåren sykdom. De vanligste og mest plagsomme problemene etter flåttbårne infeksjoner er restlammelser, smerter, utmattelse, kognitive plager og redusert arbeidsevne $(\underline{2} 3, \underline{28}, \underline{29}$.). Dette ses ved andre tilstander også. Derfor er brede differensialdiagnostiske avklaringer i forkant av rehabilitering viktig.

«Utredningsforløpet har som mål å bekrefte eller avkrefte flåttbåren sykdom som årsak til pasientens plager. Et annet mål er å avdekke andre mulige forklaringer, gi anbefalt behandling og eventuelt rehabilitering» 
Personer som har hatt disseminert borreliose, eller gjennomgått skogflåttencefalitt, anbefales rutinemessig fulgt opp av spesialisthelsetjenesten tre måneder etter gjennomført behandling (eventuelt seks måneder). Det vil kartlegge eventuelle restplager og avklare behov for supplerende utredning og differensialdiagnostikk.

Forskning på rehabiliteringstiltak for denne gruppen er svært begrenset. Det finnes ingen diagnosespesifikke rehabiliteringstiltak. Anbefalingene følger generelle prinsipper for rehabilitering.

\section{LITTERATUR}

1. Meldingssystem for smittsomme sykdommer (MSIS) ved Folkehelseinstituttet. http://www.msis.no/ Lest 25.2.2021.

2. Lyngstad TM, Astrup E, Brandal LT et al. Årsrapport 2019: Overvåking av infeksjonssykdommer som smitter fra mat, vann og dyr, inkludert vektorbårne sykdommer. Oslo: Folkehelseinstituttet, 2020. https://www.fhi.no/globalassets/dokumenterfiler/rapporter/2020/2019_arsrapp_mat_vann_dyr.pdf Lest 25.2.2021.

3. Eliassen KE, Berild D, Reiso $\mathrm{H}$ et al. Incidence and antibiotic treatment of erythema migrans in Norway 2005-2009. Ticks Tick Borne Dis 2017; 8: 1-8. [PubMed][CrossRef]

4. Nasjonale faglige retningslinjer for antibiotikabruk i primærhelsetjenesten. Borreliose. http://www.antibiotikaiallmennpraksis.no/index.php?action=showtopic\&topic=ZfgZUXe2 Lest 25.2.2021.

5. Harbo S, Blystad H, Nilsen S et al. Diagnostikk og behandling av Lyme borreliose - Rapport til Helsedirektoratet fra arbeidsgruppen. Oslo: Helsedirektoratet, 2009.

https://www.helsedirektoratet.no/rapporter/rapport-om-diagnostisering-og-behandling-av-lymeborreliose-

flattsykdom/Rapport\%20om\%2odiagnostisering\%20og\%2obehandling\%2oav\%2olyme\%2oborreliose\%2 ofl\%C $3 \%$ A5ttsykdom.pdf/_/attachment/inline/77022134-ede7-4157-85aa-

489o8d19c036:4a114C13a1a314fb40e579b51581a6o602205b61/Rapport\%20om\%2odiagnostisering\%20og\% 2obehandling\%20av\%2olyme\%2oborreliose\%2ofl\% 3 \% $\%$ Attsykdom.pdf Lest 25.2.2021.

6. Statens beredning för medicinsk och social utvärdering. Behandlingstid vid borreliainfektion. https://www.sbu.se/sv/publikationer/SBU-utvarderar/behandling-med-antibiotika-for-patienter-medborrelia/ Lest 25.2.2021.

7. Läkemedelsverket. Antibiotika vid borreliainfektion - behandlingsrekommendation. https://www.lakemedelsverket.se/sv/behandling-och-

forskrivning/behandlingsrekommendationer/sok-behandlingsrekommendationer/antibiotika-vidborreliainfektion-behandlingsrekommendation Lest 25.2.2021.

8. Dessau RB, Bangsborg J, Hansen Ket al. Lyme Borreliose: Klinik, diagnostik og behandling i Danmark. 2. utg. Dansk Selskab for Klinisk Mikrobiologi, Dansk Selskab for Infektionsmedicin og Dansk Neurologisk Selskab, 2014.

http://dskm.dk/onewebmedia/Borrelia\%2oklaringsrapport\%202.udgave\%202014.pdf Lest 25.2.2021.

9. Institutet för hälsa och välfärd. Borrelia. https:/|thl.fi/sv/web/infektionssjukdomar-ochvaccinationer/sjukdomar-och-bekampning/sjukdomar-och-sjukdomsalstrare-a-o/borrelia Lest 25.2.2021.

10. Rapport: Nordisk konsensus om utredning og oppfølging av personer med langvarige plager ved mistenkte flåttbårne sykdommer. Oslo: Helsedirektoratet, 2020.

https://www.helsedirektoratet.no/rapporter/nordisk-konsensus-om-utredning-og-oppfolging-avpersoner-med-langvarige-plager-ved-mistenkte-flattbarne-sykdommer Lest 25.2.2021.

11. Flåttsenteret. BorrSci - et stort norsk forskningsprosjekt på borreliose. https:/|xn-flttsenteretucb.no/forskning/1051-2/ Lest 25.2.2021.

12. Reiso H. Lyme borreliosis; a scientific approach to reduce diagnostic and therapeutic uncertainties. Årsrapport som eRapport 2021.

https://forskningsprosjekter.ihelse.net/home/prosjekt/2015113 Lest 25.2.2021.

13. Aavitsland P. En epidemi av borreliose? NRK Ytring 10.5.2013. https://www.nrk.no/ytring/enepidemi-av-borreliose_-1.11021298 Lest 25.2.2021.

14. Eliassen KE, Lindbæk M, Noraas S et al. Ensidig og feilaktig om flått. Dagbladet 25.10.2012. https://www.dagbladet.no/kultur/ensidig-og-feilaktig-om-flaringtt/63241782 Lest 25.2.2021.

15. The International Lyme and Associated Diseases Society (ILADS). Controversies \& Challenges in Treating Lyme and Other Tick-borne Diseases. https://www.ilads.org/research-literature/controversies- 
challenges/ Lest 25.2.2021.

16. ArmiLabs - Diagnosing tick-borne diseases. https://arminlabs.com/en Lest 25.2.2021.

17. Laboratories RED. Phelix Phage borrelia test. https://redlabs.be/ Lest 25.2.2021.

18. Aase A, Hajdusek $O$, Øines $\emptyset$ et al. Validate or falsify: Lessons learned from a microscopy method claimed to be useful for detecting Borrelia and Babesia organisms in human blood. Infect Dis (Lond) 2016; 48: 411-9. [PubMed][CrossRef]

19. Tveten Y, Noraas S, Aase A. Cellulære borreliatester. Tidsskr Nor Legeforen 2014; 134: 146-7. [PubMed][CrossRef]

20. Ulvestad E. Borreliosestriden. Tidsskr Nor Legeforen 2013; 133: 2234. [PubMed][CrossRef]

21. Jacquet C, Goehringer F, Baux E et al. Multidisciplinary management of patients presenting with Lyme disease suspicion. Med Mal Infect 2019; 49:112-20. [PubMed][CrossRef]

22. Kirkehei I, Flottorp S, Aaberge I et al. Laboratoriadiagnostikk ved flåttbårne infeksjoner: Systematisk litteraturs $\varnothing \mathrm{k}$ med sortering. Oslo: Folkehelseinstituttet, 2019. https://www.fhi.no/publ/2019/laboratoriadiagnostikk-ved-flattbarne-infeksjoner/ Lest 25.2.2021.

23. Coumou J, Herkes EA, Brouwer MC et al. Ticking the right boxes: classification of patients suspected of Lyme borreliosis at an academic referral center in the Netherlands. Clin Microbiol Infect 2015; 21:368.e11-20. [PubMed][CrossRef]

24. Gynthersen RMM, Tetens MM, Ørbæk M et al. Classification of patients referred under suspicion of tick-borne diseases, Copenhagen, Denmark. Ticks Tick Borne Dis 2021; 12: 101591. [PubMed] [CrossRef]

25. Zomer TP, Bruinsma RA, Vermeeren YM et al. Nonspecific symptoms in children referred to a Lyme Borreliosis Center. Pediatr Infect Dis J 2020;39: 775-80. [PubMed][CrossRef]

26. Ogrinc K, Maraspin V, Lusa L et al. Acrodermatitis chronica atrophicans: clinical and microbiological characteristics of a cohort of 693 Slovenian patients. J Intern Med 2021; 289: joim.13266. [PubMed][CrossRef]

27. Nemetha J, Bernasconib E, Heiningerc U et al. Update of the Swiss guidelines on post-treatment Lyme disease syndrome. Swiss Med Wkly 2016;146: w14353. [CrossRef]

28. Eikeland R, Ljøstad U, Helgeland G et al. Patient-reported outcome after treatment for definite Lyme neuroborreliosis. Brain Behav 2020;10: e01595. [PubMed][CrossRef]

29. Eikeland R, Mygland A, Herlofson Ket al. European neuroborreliosis: quality of life 30 months after treatment. Acta Neurol Scand 2011; 124:349-54. [PubMed][CrossRef]

Publisert:3. mai 2021. Tidsskr Nor Legeforen. DOI:10.4045/tidsskr.20.10o6

Mottatt 7.12.2020, første revisjon innsendt 11.3.2021, godkjent 15.3.2021.

(C) Tidsskrift for Den norske legeforening 2023. Lastet ned fra tidsskriftet.no 26. april 2023. 